\title{
The B-team: Equal but different?
}

Luke Pembroke

As a person with haemophilia $B, I$ have known there are differences between haemophilia $A$ and haemophilia $B$ and their respective treatment throughout my life - though I was shocked when I learnt about the impact inhibitors can have when it comes to bleeding. Despite being very rare, as well as difficult to manage, in a recent survey reported by Chaplin et al., many nurses had experience in managing haemophilia $B$ inhibitors. Nurses in the survey also thought extended half-life $(E H L)$ factor products would remain the optimal treatment for haemophilia B in 2025. Ongoing clinical trials for novel molecules like concuzimab and fitusiran signal the start of more treatment options for haemophilia $B$, and the development of gene therapy has focused on haemophilia B in the first instance. But the fact remains that the pharmaceutical industry has focused on developing treatments for the larger haemophilia A market. Could this have distorted perceptions around treatment? In a further 'perception bias' that impacts management, some nurses feel there are differences in bleeding phenotype between haemophilia A and B. Garner et al.'s paper discussing rIX-FX, suggests that treatment adherence is better in

This commentary relates to the following papers:

- Garner K, Guelcher C, Pollard D. The use of rIX-FP in patients with haemophilia B: a nurse's perspective. J Haem Pract 2021; 8(1): 86-97. doi: 10.17225/jhp00180

- Chaplin S, Friberg Berkedal M, Crilly E, et al. Haemophilia specialist nurses' perceptions of haemophilia B. J Haem Pract 2021; 8(1): 119-127. doi: 10.2478/jhp-2021-013

LUKE PEMBROKE

Creative Director, Haemnet, UK, and Patient Advocate.

Email: lukeahaemnet.com

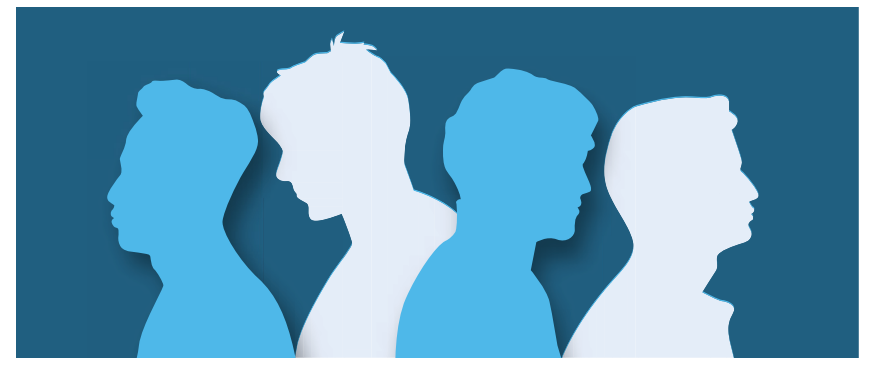

haemophilia B due to lower dosing frequency, making it an easier treatment option than for haemophilia $A$. The patient perception may be somewhat different. While dosing schedules in haemophilia $B$ have been more consistent for longer, there has been less pharmacokinetic modelling in haemophilia B and, arguably, less opportunity for truly tailored treatment. Gene therapy has been shown to be more 'successful' for haemophilia B than haemophilia A, but emicizumab has raised questions about the need for gene therapy in haemophilia A. Having an 'emi-equivalent' for haemophilia $B$ will raise the same questions and may give people haemophilia $B$ and inhibitors an effective treatment that is as transformative as emicizumab has been in the haemophilia A population.

Keywords: haemophilia B, factor IX, novel therapies, patient views

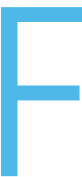

rom as early as I can remember, I was aware there was a difference between haemophilia $A$ and haemophilia B. My mother was well informed about haemophilia - she was particularly taken about the connection to the royal family - and spoke to my school teachers authoritatively about my haemophilia. At primary school, there was someone with haemophilia $A$ in the year below me: she knew from my haemophilia centre that the distinction was an important one in terms of treatment.

This is an Open Access article distributed under the terms of the Creative Commons Attribution-NonCommercial-NoDerivs License (https://creativecommons.org/licenses/by-nc-nd/3.0/) which permits use and distribution in any medium, provided the original work is properly cited, the use is non-commercial, and no modifications or adaptations are made. Copyright is retained by the authors. 
Growing up I had a lot of bleeds. I've heard from several consultants over the years that I appeared to have a particularly high ABR 'for a haemophilia B'. I learnt early on that haemophilia A was treated on Mondays, Wednesdays and Fridays, and haemophilia $B$ was treated on Mondays and Thursdays. Whenever I went to patient events, I was aware that those with haemophilia A treated more often than me. In time I learned that it was due to differences in half-life - it never occurred to me that we might have differences in the number of bleeds we experienced. At youth camps organised by the Haemophilia Society, when discussing our bleeds, it was the same experience. The main difference we picked up on between each other was whether we had good veins or bad veins.

It was only when I met someone with haemophilia A and an inhibitor at a youth camp aged 16 that it became clear just how much of an impact inhibitors can have when it comes to bleeding. We were all shocked that he had to treat every day, sometimes twice a day. He also had to use a combination of $30 \mathrm{ml}$ and $20 \mathrm{ml}$ syringes to administer treatment. This wasn't something I'd seen since receiving plasma-derived treatment when I was younger. l'd become use to my recombinant treatment kit which only required two $5 \mathrm{ml}$ prefilled syringes.

It was a long time before I met someone with a haemophilia B inhibitor. He appeared to have it well managed but had noticeable joint damage and had experienced significantly more bleeds than I had growing up. It is very rare to meet people with haemophilia B and inhibitors at patient meetings - it may be, of course, that they are unable to access meetings because their condition is so debilitating. So, it is interesting that so many nurses in a survey reported by Chaplin et al. had experience in managing haemophilia B inhibitors; they are very rare and very difficult to manage ${ }^{[1]}$.

In the survey, most nurses felt that extended halflife products would remain the optimal treatment for haemophilia B in 2025. Over the past two decades, people with haemophilia $B$ have seen less change in treatment options than those with haemophilia A. Conversations about switching to different treatments are not straightforward. Also discussing haemophilia B, Garner et al. recognise that patients can be reluctant to have conversations about changing product if they feel their current treatment works for them ${ }^{[2]}$. It's possible that conversations about switching to different treatments are more difficult with people with haemophilia B, purely because most have not been offered anything new for a long time. Following the arrival of emicizumab, I have heard from parents of children with haemophilia B, "Is there something like that for haemophilia B?" Despite the benefits associated with EHL-FIX treatments, the burden of intravenous injection can't be ignored.

We have started to see more treatment opportunities for people with haemophilia B, particularly those with inhibitors who have few other options at present, with ongoing clinical trials for novel molecules such as concizumab and fitusiran. We know that the factor IX molecule is smaller than that for factor VIII, which has led to the development of gene therapy for haemophilia focusing first on haemophilia B [3]; developing gene therapy for haemophilia $A$ has been described as 'more difficult' ${ }^{[4]}$. But the fact remains that the pharmaceutical industry has focused on developing treatments for the larger haemophilia A market. Could this have distorted perceptions around treatment?

A further 'perception bias' is seen in the Chaplin paper, where one third of nurses felt there was a difference in bleeding phenotype; that those with haemophilia B bleed less than those with haemophilia $A$, and that this impacts on management. This probably reflects the fact that there are fewer people with haemophilia B than with haemophilia A, so there is less awareness of the bleeding. It's also likely nurses see these patients less often overall. While those with moderate and mild haemophilia B do generally fare better versus those with moderate and mild haemophilia A, for those with severe haemophilia there is little difference when it comes to experiencing a bleed. You only have to look at the natural history of haemophilia to recognise the time it took to distinguish and identify haemophilia B.

The Garner paper talks about adherence in relation to dosing frequency ${ }^{[2]}$. It suggests that adherence is better in haemophilia B because you only have to inject once a week or maybe once a fortnight for some of the newer extended half-life products in adults, making this an easier treatment option than haemophilia $A$. The patient perception of different dosing intervals is variable between individuals. For those with haemophilia A treating every other day or three times a week, the option to treat once a week seems very attractive. However, from discussions I've had with people about infusion frequency, the difference between once a week vs. twice a week has often been seen as negligible. It is also fair to say that dosing schedules in haemophilia B have been more consistent for longer, and therefore subject to less disruptive changes. But there has been less pharmacokinetic 
modelling in haemophilia B than haemophilia A, from which you could argue that there has been less opportunity to truly tailor treatment. It is interesting that both the Chaplin and Garner papers talk about measuring trough levels rather than conducting full PK studies. Clinicians do not have the tools they have for haemophilia A. There is also the extravascular distribution of factor IX to consider, which affects the pharmacokinetics and means that treatment can be given less frequently. Over the last few years, I have noticed more discussion at conferences and within the literature focusing on extravascular distribution of FIX. Continued research into this area is needed in order to better optimise prophylaxis for people with haemophilia $B^{[5]}$

Extended dosing intervals raise an issue of confidence. When EHL products first launched, the marketing seemed to largely focus on the idea of convenience. A growing understanding in the community around the importance of maintaining higher trough levels drew some attention away from the benefit of 'fewer injections' [6,7]. To dose every 14 days could generate anxiety around bleeding and not having adequate protection. This highlights the importance of shared decision making and ensuring patients are educated and informed about their treatment ${ }^{[8]}$. For some patients, trough levels of 3-4\% may not be sufficient in prevention of bleeding. Both the Chaplin and Garner papers emphasise the importance of having a haemophilia care team that supports patients in understanding their treatment options. However, neither really touches on the impact of gene therapy, which might be more 'successful' (based on level and duration of FIX expression in clinical trials ${ }^{[9,10]}$ for haemophilia B than for haemophilia A, even if it is not the first to market.

The issue with gene therapy then becomes 'better than what?'. Is it better than the treatments we have now? Or will it better than treatments that are in development? Emicizumab has raised further questions about the need for gene therapy in haemophilia A. I have been asked at a WFH event, whether I would have enrolled in a gene therapy trial if I had haemophilia A. I am increasingly hearing accounts from people treating with emicizumab that 'it is like not having haemophilia'. For haemophilia B we do not yet have an 'emiequivalent' - but I hope we do have something like this soon. I particularly hope to see an effective treatment for people with haemophilia B and inhibitors that has as transformative results as emicizumab has done for the haemophilia A population. And it will be important to capture and publish patient insights and experiences alongside the clinical data as novel therapies for haemophilia B are developed.

\section{ACKNOWLEDGEMENTS}

The authors have advised no interests that might be perceived as posing a conflict or bias.

This article does not contain any studies involving human participants or animals performed by any of the authors.

\section{ORCID}

Luke Pembroke (iD) https://orcid.org/0000-0002-2024-6898

\section{REFERENCES}

1. Chaplin S, Birkedal MF, Crilly E, et al. Haemophilia specialist nurses' perceptions of haemophilia B. J Haem Pract 2021; 8(1): 119-127. doi: 10.2478/jhp-2021-0013.

2. Garner K, Guelcher C, Pollard D. The use of rIX-FP in patients with haemophilia B: A nurses' perspective. $J$ Haem Pract 2021; 8(1): 86-97. doi: 10.17225/jhp00180.

3. Murphy SL, High KA. Gene therapy for haemophilia. $\mathrm{Br}$ J Haematol 2008; 140(5): 479-87. doi: 10.1111/j.13652141.2007.06942.x.

4. UCL research leads to haemophilia gene therapy success. 15 December 2017. UCL. Available at https://www.ucl.ac.uk/ news/2017/dec/ucl-research-leads-haemophilia-genetherapy-success (accessed 27 September 2021).

5. Mann DM, Stafford KA, Poon MC, Matino D, Stafford DW. The Function of extravascular coagulation factor IX in haemostasis. Haemophilia 2021; 27(3): 332-339. doi: 10.1111/hae.14300.

6. Castaman G. The benefits of prophylaxis in patients with hemophilia B. Expert Rev Hematol 2018; 11(8): 673-683. doi:10 .1080/17474086.2018.1489719.

7. Srivastava A, Santagostino E, Dougall A, et al.; WFH Guidelines for the Management of Hemophilia panellists and co-authors. WFH Guidelines for the Management of Hemophilia, 3rd edition. Haemophilia 2020; 26 Suppl 6: 1-158. doi: 10.1111/ hae.14046.

8. Valentino L, Blanchett V, Negrier C, et al. Personalising haemophilia management with shared decision making. J Haem Pract 2021; 8(1): 69-79. doi: 10.17225/jhp00178.

9. Nathwani AC, Reiss UM, Tuddenham EG, et al. Long-term safety and efficacy of factor IX gene therapy in hemophilia B. N Engl J Med 2014; 371(21): 1994-2004. doi:10.1056/ NEJMoa1407309.

10. Von Drygalski A, Giermasz A, Castaman G, et al. Etranacogene dezaparvovec (AMT-061 phase 2b): normal/near normal FIX activity and bleed cessation in hemophilia B. Blood Adv 2019; 3(21): 3241-3247. doi: 10.1182/bloodadvances.2019000811.

HOW TO CITE THIS ARTICLE:

Pembroke L. The B-team: Equal but different? J Haem Pract 2021; 8(1): 133-135. https://doi.org/10.2478/jhp2021-0014. 